\title{
"Estado de guerra", democracia aparente y "razón crítica"
}

Enrique Dussel

En ocasión del Ix Seminario del Diálogo Filosófico Norte-Sur con la presencia de mis colegas Karl-Otto Apel, Franz Hinkelammert, Georges Labica y tantos otros amigos, desearía presentar a la discusión algunas tesis que se me imponen desde la gravedad de la situación mundial, que nos interpela como filósofos, particularmente, en el nivel de la ética y la filosofía política.

\section{Algo de geopolítica después de $\mathbf{1 9 8 9}$}

Desde el "derrumbe de la Unión Soviética", la humanidad, como un todo, vive una experiencia política de la que los filósofos parecieran no haber comprendido su importancia estratégica, teórica y ética. Por primera vez en la Historia Mundial, sensu strictu, y aún más, por primera vez desde que la especie bomo adoptó la forma erecta hace millones de años, el Globo Terráqueo, nuestro pequeño planeta Tierra, se encuentra bajo el poder militar de una sola potencia: Estados Unidos. Su hegemonía no es cultural ni política, y aún en la economía su poder va proporcionalmente en declive, pero militarmente, desde 1989, tiene una indiscutida primacía, que se ha manifestado en tres guerras situadas en el Tercer Mundo - ya que Europa Oriental se ha 
"tercermundizado"- Estados Unidos tiene, después de esta fecha, clara intención de constituir al mundo cuasiperiférico socialista de la antigua Unión Soviética en su propia periferia capitalista.

Ante la guerra de Afganistán (y su secuela en Israel contra palestinos inocentes) que contemplamos atónitos y apesadumbrados diariamente, el intelectual Samuel Huntington pudiera hacernos creer que se trata tanto de El choque de civilizaciones, como de una Reconfiguración del orden mundial'; siendo, en realidad, algo más simple y claro, pero cuyo sentido se encuentra encubierto por una maraña de argumentos y declaraciones puramente aparentes. Henry Kissinger enseñó que la geopolítica no se inspira en "buenas intenciones", sino en la defensa de los "propios intereses". Se nos inculca a diestra y siniestra que se trata de una "cruzada contra el terrorismo", como si la CIA no fuera la maestra del terrorismo en África (contra Angola y Mozambique, por ejemplo); en América Latina, incentivado desde 1954 (desde el golpe de estado contra Jacobo Arbenz); pasando por la invasión de Bahía de los Cochinos, en Cuba; por los "contras" (terroristas contra el gobierno democrático de Nicaragua, que destituyó al tirano Somoza, educado en las escuelas militares del Norte), y en la actual "Guerra de Colombia"; en el Medio Oriente (desde la caída de Nasser en 1954); en Asia (desde el golpe contra Sukarno en el mismo año), hasta el presente. Como si los terroristas hoy perseguidos en Afganistán no fueran los disciplinados "aprendices de mago" de esa misma escuela (es decir, discípulos que pasan de los "servicios de inteligencia" de un bando a otro, como Noriega en Panamá, o como los grupos armados de los fundamentalistas islámicos contra la antigua URSS en Afganistán, para después ser perseguidos, encarcelarlos o destruirlos como terroristas cuando ya no sirven a "nuestros intereses"). "Terrorista" es, según la definición hoy vigente, el que atenta contra "nuestros intereses". Los terroristas de hoy se "equivocan", porque no saben que "nuestros intereses" han cambiado, y permanecen tercamente sosteniendo "nuestras enseñanzas" contra nuestros "enemigos" de ayer, o, aún peor, cuando pretenden descubrir ellos mismos a sus nuevos "enemigos" (sus maestros de terrorismo de ayer).

En las últimas tres guerras ha habido una escalada. Estados Unidos, durante la Guerra Fría -así llamada por los productores de armas, no por los pueblos de Vietnam, Mozambique, Nicaragua o Afganistán, que debieron usarlas contra sus hermanos-, fue el ba- 
luarte del derecho internacional desde la ONU y otros organismos, para oponerse a la URSS. Desde 1989, ya no es más necesaria esta política. Peter Spiro ${ }^{2}$ muestra cómo Estados Unidos se retira de todos los organismos internacionales, y aún se opone a ellos (no pagaba las cuotas a la ONU, no apoya un Tribunal Internacional [ICC], no firma el Protocolo de Kyoto, no permite redefinir los fines del Banco Mundial y del FMl, se opone contra una efectiva fuerza internacional de paz de la ONU, no aprueba la Ley de Convención del Mar, ni la Convención de Diversidad Biológica, etc.). El mismo millonario filántropo George Soros $^{3}$, sugiere la necesidad de constituir instituciones internacionales para implementar una paz duradera y evitar la futura gran crisis global financiera que anuncia, pero que encuentra a Estados Unidos como el enemigo principal de tales medidas e instituciones políticas globales. Soros llama a la doctrina del norteamericano aislacionista el nuevo "fundamentalismo del mercado" (market fundamentalism) ${ }^{4}$, al que pertenece ciertamente el equipo de George W. Bush. Propone, en oposición a la actual política exterior norteamericana, una "Alianza de los Estados democráticos” de toda la tierra. Debo reconocer que, paradójicamente, la obra de Soros es mucho más interesante, progresista y realista que la visión postmoderna de Hardt-Negri ${ }^{5}$.

En efecto, si consideramos, aunque sea superficialmente, los últimos tres conflictos armados, podemos ver que hay un creciente "aislacionismo", o un aumento de autonomía en el obrar de Estados Unidos. En la Guerra del Golfo se obró con el apoyo de la ONU, de la OTAN, de los países árabes y de muchos del Tercer Mundo. En la guerra de Kosovo, sólo se contó con la OTAN. En la guerra de Afganistán se decidió y se operó solo. No hubo necesidad de ninguna colaboración efectiva de nadie, fuera del ejército norteamericano (la intervención de Blair, con los soldados ingleses, o de los alemanes, etc., es puramente simbólica). Puede, entonces, confirmarse una vez más la hipótesis de la política de los "new sovereignists" de Spiro, y del "fundamentalismo de mercado" de Soros.

Pero, al final y estratégicamente, equé se ha intentado en estas tres guerras? Siempre un mismo objetivo: la expansión global de la presencia militar - como garantía de la expansión del mercado global, con especial referencia a la fuente principal de energía: el petróleo-. La Guerra del Golfo permitió a Estados Unidos imponer su presencia, para siempre, en Arabia Saudita (la "Tierra Santa" del Islam) y en 
Kuwait (en la parte central del Medio Oriente petrolero). La guerra de Kosovo, no dirigida por petroleros, situó en lugar secundario a la Rusia post-URSS (que ya no pudo ayudar a su aliado eslavo, serbio y ortodoxo) y movió a su voluntad a Europa con la OTAN. En la guerra de Afganistán, Estados Unidos ha instalado bases militares en el Norte de Afganistán, para siempre; y sea cual sea el nuevo gobierno y su orientación, le deberá al Pentágono haber destruido al Talibán; es decir, le será dependiente y le permitirá pasar el gas y el petróleo de sus vecinos por su territorio, además de otros servicios eventuales en el futuro. Además, se encuentra ahora como "vecino" de China, Rusia e India, los tres poderes asiáticos por excelencia.

Fsta geopolítica militar manifiesta no sólo una "voluntad de poder" omnímoda y que no acepta compartir la hegemonía con nadie (menos aún con una Europa alejándose geopolíticamente del equipo de George W. Bush), sino también, y principalmente para el filósofo, una racionalidad política que puede ser analizada éticamente, y que determina el horizonte interpretativo de la Filosofía Política al comienzo del siglo XXI -filosofía que tenga alguna pretensión de pensar "lo real" y no meras piezas arqueológicas-.

\section{2. "Estado de guerra” y la "razón tautológica” del Imperio}

El mundo anglosajón, que inicia su hegemonía con el Imperio inglés, como es sabido, nace, ante todo, gracias a la piratería. Francis Drake y muchos otros, entre 1585 y 1603, cuentan hasta con 183 barcos que realizan 74 ataques mayores. La explotación del azúcar en Barbados da la oportunidad para comenzar la trata de esclavos - con cincuenta individuos- ${ }^{6}$. John Selden, con su Ductor Dubitandum (publicado en Londres en 1660) demuestra que es de derecho natural y fundado en el Antiguo Testamento el ocupar las nuevas tierras descubiertas y, "therefore to save my own life, I can kill another, or twenty, or hundred, or take from his hands to please myself"'. John Vaughan o Thomas Hobbes opinarán de la misma manera.

Después de la "Glorious Revolution", la visión tradicional del pensamiento liberal queda expresada en la posición de el primero entre sus pares $^{8}$, de un John Locke (1632-1704) ${ }^{9}$. Lo tratamos aquí porque constituye un capítulo abierto y que no se cerrará, de una u otra manera, hasta el presente, porque aún en nuestro tiempo se siguen esgrimien- 
do argumentos filosóficos políticos dentro de la "lógica" que Locke expone sobre el tema, en especial, en el ámbito de la política global y en los foros internacionales ${ }^{10}$. Se trata de una aplicación particular de la "lógica de la totalidad" ", pero con una coherencia tautológica ejemplar, que permite justificar, dentro del espíritu de la revolución inglesa de 1688, la trata de esclavos (y la esclavitud como institución), business en el que Locke privadamente tenía invertido alguno de sus haberes, pero también en el mundo colonial, a partir de los mismos argumentos. En el segundo de los Two Treatises on Civil Government, publicado en 1690 , se ocupa frecuentemente de estos temas. Opuesto a la Iglesia Anglicana y al absolutismo monárquico del partido tory, expresó de manera secularizada y agresiva la nueva posición burguesa de los whigs. La trata de esclavos era un comercio en auge, lo mismo que el establecimiento de colonias en América, donde Inglaterra competía con Portugal y España, e igualmente con Holanda.

Todo se inicia con una declaración universal sobre la igualdad:

[El estado natural] es también un estado de igualdad [...] en el que nadie tiene más que otro [...] nacidos para participar sin distinción de todas las ventajas de la naturaleza [...]; siendo también iguales entre ellos, sin subordinación, ni sometimiento. ${ }^{12}$

Ante tal declaración, sería de esperar la imposibilidad de la esclavitud y de un mundo colonial. Pero no es así. ¿Cómo se las arregla Locke para poder justificar la esclavitud y un mundo colonial? Su argumentación parte de la exigencia de la conservación de la vida propia y de los demás ${ }^{13}$ en el "estado de naturaleza", de donde se deduce que no puede negarse el derecho de castigar a los que no cumplen con la ley natural, y por ello, "tiene cualquiera el derecho de castigar a los transgresores de esta ley [... Este] defiende de ese modo a los inocentes, poniendo un obstáculo a los culpables"14. El transgresor, por el hecho de no cumplir con la ley, "viene a manifestar que con él no rige la ley de la razón y la equidad común [...] Al hacerlo, se convierte en un peligro para el género humano"15.

La pregunta obvia sería: ¿Quién y cómo puede determinar el crimen del culpable? ¿Cómo se elige al juez que pueda "defender a la especie humana en general' ${ }^{16}$ "? La respuesta de Locke, suponiendo que nos encontramos en el "estado de naturaleza", pareciera simple y evidente: "cualquier hombre tiene el derecho de castigar a un culpable"17. 
El culpable, por haberse opuesto a la ley natural ${ }^{18}$, queda desprovisto de derechos, ya que "no rige con él la razón". Pero, para poder atacar al culpable, es necesario pasar del mero "estado de naturaleza" al "estado de guerra", que para Hobbes se daban simultáneamente. Para Locke, por el contrario, el estado de naturaleza no es el estado de guerra; se entra en el "estado de guerra" cuando hay alguien que se opone a la ley natural o nos odia sin motivo justo:

Se puede destruir a un hombre [...] que ba manifestado odio contra nosotros ${ }^{19}$, por la misma razón que podemos matar a un lobo o a un león. Esa clase de hombres no se someten a los lazos de la ley común de la razón; por ello pueden ser tratados como fieras ${ }^{20}$.

Quien trata de esclavizarme se coloca a si mismo en estado de guerra conmigo [...] La libertad es la base de todo ${ }^{21}$.

En el "estado de guerra" no impera ya el "estado de naturaleza", pero tampoco el "estado civil" o político. Es justamente para superar el estado de naturaleza y evitar el estado de guerra, es decir, para poder tener un juez con derecho, con legitimidad, que nace de la "sociedad civil" o política (el "estado civil"). Pero un juez civil o político tiene sólo un "estado de guerra", porque les "falta un juez común con autoridad"22, y en ese caso, "soy yo el único juez dentro de mi propia conciencia"23. Como la esclavitud y las relaciones coloniales se establecen en una referencia externa a los Estados o las naciones (p. e., de Inglaterra con las comunidades africanas o americanas) no hay autoridad supranacional política para dilucidar el conflicto, sino que sólo impera el estado de guerra, cuando una nación ofende a otra nación, o cuando se ve exigida a lanzar una "guerra justa". El "estado de guerra" es, sin embargo, un "estado de excepción”, à la Carl Schmitt, en la que el Otro, la dignidad de la Alteridad es aniquilada. Esta negación de todo derecho del Otro, que, como veremos, queda nuevamente reafirmada en el concepto de "poder despótico", es lo que Locke debía probar, pero darlo como un supuesto, torna tautológico todo su argumento.

Levinas comprendió muy bien este argumento tautológico, totalitario, fundamento mismo de la Modernidad (y de la concepción de los derechos humanos ad extra de los liberales de Estados Unidos - no hablemos de los conservadores fundamentalistas-, desde el tiempo 
de la Constitución hasta la "guerra de Afganistán"24), cuando escribe en el Prefacio de Totalidad e Infinito:

El estado de guerra ${ }^{25}$ suspende la moral; despoja a las instituciones $y$ a las obligaciones eternas de su eternidad $y$, desde entonces, anula en lo provisorio los imperativos incondicionales [...] La guerra no se sitúa solamente como la mayor entre las interpelaciones de la moral. Ella la torna ridicula. El arte de prever y de ganar por todos los medios la guerra [...] se impone desde entonces como el ejercicio mismo de la razón. ${ }^{26}$

En la ética levinasiana - y en la Ética de la Liberación-, el Otro nunca puede perder sus derechos, su dignidad, y jamás podrá ser sujeto de un "poder despótico", tal como Locke pretende. Es decir, si una comunidad juzga, ya "cualquiera" tiene este derecho natural ante Dios -según Locke-, que el africano, el indio o el mexicano ha negado la ley natural, o se ha levantado en armas injustamente, o simplemente "me odia". A partir de tal "juicio", pierde de inmediato dicho extraño todo derecho y queda determinado como enemigo (el inimicus y no el bostis de Schmitt), al que se le puede declarar una "guerra justa". Si es vencido - y ahora todo depende de la tecnología militar, puro efecto de la "razón instrumental" - será definido "justamente" como esclavo o como súbdito colonial. Analicemos paso a paso el proceso argumentativo en los capítulos IV, "De la esclavitud" y XVI, "De la conquista", entre otros parágrafos referidos a los temas.

Locke sabe que Inglaterra comienza sus riquezas gracias a los piratas. Por ello comienza por desautorizarlos, partiendo de una premisa mayor o principio universal, cuando afirma:

Quienes no creen que los ladrones y los piratas poseen dominio legal sobre aquellos a quienes han logrado vencer por la fuerza [...] no otorgarán jamás derecho sobre los vencidos en una guerra injusta de esa clase ${ }^{27}$.

Hecha esta declaración para todos aceptable, pasa a exponer la posibilidad de una "guerra justa". Veamos primero el caso de la esclavitud. Continúa su argumento enunciando otro principio universal, que intentará acotar para poder justificar la esclavitud. Su estrategia argumentativa es, entonces, enunciar positivamente lo que intenta negar como excepción: 
El hombre, que no tiene poder sobre su propia vida, no puede hacerse esclavo de otro por contrato o por su propio consentimiento [...] Quien no dispone del poder de acabar con su propia vida no puede dar poder a otra persona para bacerlo ${ }^{28}$.

Pero de inmediato se introduce una excepción a la regla, partiendo del cautivo de una "guerra justa":

Sin duda alguna que quien ha perdido, por su propia culpa $a^{29}$ y mediante algún acto merecedor de la pena de muerte ${ }^{30}$, el derecho a su propia vida ${ }^{31}$, puede encontrarse con que aquel que puede disponer de esa vida ${ }^{32}$ retrase, por algún tiempo, el quitársela cuando ya lo tiene en poder suyo ${ }^{33}$, sirviéndose de él para su propia conveniencia, y con ello no le causa perjuicio alguno. Si alguna vez cree que as penalidades de su esclavitud pesan más que el valor de su vida, puede atraer sobre si la muerte que desea ${ }^{34}$, con solo que se niegue a obedecer las voluntades de su señor." ${ }^{35}$

Y concluye:

Tal es la auténtica condición de la esclavitud; ésta no es sino la prolongación de un estado de guerra entre un vencedor y un cautivo. ${ }^{36}$

De la misma manera se argumenta la posibilidad de un mundo colonial, o contra el indígena americano. Primero, la afirmación general para crear "buena conciencia": "Dios ha dado el mundo a los hombres en común" 37 . Y ahora, la excepción:

Pueden, a pesar de todo, encontrarse aún grandes extensiones de tieras cuyos habitantes no se unieron al resto del género bumano [léase: el burgués liberal inglés] en el acuerdo para el empleo del dinero común, y que permanecen incultas ${ }^{38}$.

Alli donde existen más tierras que las poseidas por sus habitantes $y$ que estos son capaces de cultivar ${ }^{34}$, alli puede cualquiera aprovecharse de las no cultivadas ${ }^{40}$.

El ocupar esas tierras, entonces, no es usurpar el derecho de nadie, ya que estaban "vacías", incultas, mal empleadas. Por supuesto que el criterio de la buena ocupación y empleo de las tierras es el de Locke (occidental, capitalista mercantil, colonialista, racista, machista, etc.)

Pero cuando no hay juez humano (porque se trata de la relación entre Estados, sin que exista un Estado internacional), “quien apela al 
cielo deberá estar seguro de que tiene el derecho de su parte"11, siendo, sin embargo, e inevitablemente, él mismo su último juez empírico:

Pero, suponiendo que la victoria favorezca al bando que tiene de su parte el derecho, pasemos a estudiar la situación del que triunfa en una guerra justa, y veamos el poder que le da la victoria, y contra quién se lo da [...] En mi entender, se trata de un poder totalmente despótico ${ }^{42}$. El conquistador detenta un poder absoluto sobre la vida de quienes, por baber becho una guerra injusta, han perdido su derecho a la vida."

Y como al conquistador se le deberá "indemnizar de los daños que ha sufrido en la guerra"*4, podrá apropiarse de los bienes de los conquistados "como gastos de guerra".

Si repasamos el argumento, podemos comprender que se ha dado una conclusión tautológica. El propio actor define quién es el enemigo y da la razón de la "justicia" de su guerra contra el dicho enemigo. De hecho, se ha ejercido el poder del más fuerte, del mejor equipado técnicamente en el arte y la estrategia militar. En realidad, la Modernidad se impuso siempre sobre los amerindios y los africanos (desde el siglo XVI) simplemente y en última instancia por la violencia de las armas. Pero esto no puede aceptarse en la "civilización" como una razón suficiente. A esta acción ilegítima hay que darle una "apariencia" moral. Locke intenta, entonces, encontrar esas "razones" dentro de la tradición.

En efecto, se inspira en Aristóteles cuando distingue entre un "poder despótico" (despoteia) y un "poder político"ts. A plica así la conocida distinción entre el poder en el "estado de naturaleza" o en el "estado político", del ejercicio del poder en el "estado de guerra", e invierte los hechos (ya que los africanos o los indigenas americanos son los atacados injustamente y se los describe como agresores). Repitamos su argumento:

Poder despótico es el [poder] absoluto y arbitrario que permite a un hombre atentar contra la vida de otro cuando asi le agrade ${ }^{\text {th }}[\ldots] \mathrm{El}$ agresor se ha salido de la ley de la razón que Dios" estableció como regla para las relaciones entre los hombres y de los recursos pacificos que esa regla enseña ${ }^{\text {th }}$, recurriendo a la fuerza para imponer sus pretensiones injustas y carentes de derecho (... Por esa razón, los prisio- 
neros capturados en una guerra justa y legítima, y solamente ellos se encuentran sometidos a un poder despótico [...] que es, en el fondo, una prolongación del estado de guerra ${ }^{49}$.

El poder que un conquistador adquiere sobre aquellos a quienes vence en una guerra justa es totalmente despótico. ${ }^{\text {so }}$

Para Locke, como en el caso de las relaciones entre Estados, no se retorna simplemente al "estado de naturaleza" (como para Hobbes, o posteriormente, para Hegel), sino que se accede a un "estado de guerra" permanente. Y, como hemos citado ya en Levinas, "el estado de guerra suspende la moral, pero se puede probar su legitimidad dentro de otra lógica, la del "estado de guerra", "lógica totalitaria" de la Modernidad, cuyo silogismo resumido es aproximadamente el siguiente:

1. En el estado de naturaleza todos son iguales y libres.

2. Si alguien deja de cumplir la ley natural, se transforma en un "fuera de la ley", en el "enemigo", que puede ser muerto como las fieras salvajes, por ser peligroso para la comunidad. No se le atribuye ya igualdad y libertad. Se actúa, entonces, en el horizonte del estado de guerra.

3. El juez con autoridad sólo existe en el estado civil o político. En la relación entre los Estados, y más con respecto al mundo colonial objeto de conquista, no hay autoridad suprema (porque no hay un Estado mundial). Nos encontramos igualmente en un estado de guerra.

4. Cuando un Estado cualquiera juzga que otro lo ha agredido, o lo haya tratado con injusticia, o simplemente lo odia, juzga a dicho Estado o nación como el agresor y, por ello, lo define como el enemigo fuera de la ley y del derecho, contra el que puede declararse una guerra justa. Sólo Dios puede juzgar la falsedad de este juicio práctico.

5. El vencedor (evidentemente, el más fuerte, el mejor armado) puede entonces esclavizar al vencido, constituirlo como esclavo o como colonia conquistada, porque estando fuera de la ley y del derecho, se tiene sobre él poder despótico, como poder justo y legítimo. Además, los bienes de los vencidos resarcen las pérdidas de la guerra justa. 
Como puede observarse, esta argumentación produce una completa inversión de lo que acontece en realidad y, además, es puramente tautológica en su sentido ético y político. Primero, porque al inocente campesino africano, indígena americano o comunidad colonial se lo ha definido como un violento agresor (inversión de los hechos empíricos). Segundo, porque el "juez" (en el cuarto momento de la argumentación), aunque no tiene autoridad o poder político por no estar en condiciones de ser miembros de un inexistente Estado mundial, se encuentra en un inevitable estado de guerra. Si en este "estado" resulta vencedor, y teniendo sólo a Dios por juez, posee sobre los vencidos legítimamente poder despótico. Con estas razones, todo Estado puede juzgar a cualquier otro como "fuera de la ley", simplemente por no cumplir con su interpretación "cultural" o etnocéntrica de la ley natural o de lo que Dios [el nuestro] estableció como regla. Se trata de una tautología autoreferente radical, sin ningún criterio objetivo o referencia de empírica exterioridad universal. Es lo puramente subjetivo, arbitrario, intracultural, dogmático, totalitario. Este argumento, sin embargo, expresa la racionalidad misma de la "Razón moderna", esclavista y colonial; es decir, fundamentó (aparentemente) el comporamiento de las metrópolis europeas hacia el mundo colonial y hacia la esclavitud de la Modernidad, hasta el presente: es exclusión radical de la dignidad de la Alteridad, del derecho de la Identidad propia del africano esclavizado, del indígena americano, del mundo colonial, contra toda razón.

Sin embargo, cuando leemos en los diarios y escuchamos en la televisión que el Secretario de Estado (el general Colin Powell) anuncia que Estados Unidos deberá continuar la guerra contra los "terroristas", aunque fuera solo - ante la negativa europea, rusa o china por seguir la guerra contra Irak o Irán, habiendo, sin embargo, ya comenzado la de la "Guerra de Colombia"-, se repite una vez más el argumento de Locke: en el "estado de guerra", el Estado hegemónico se afirma como juez para decidir quién es su enemigo (en este caso, los "terroristas" ${ }^{51}$ ), y en referencia última, al propio juicio de Dios ${ }^{52}$.

\section{La "doble moral" o el cinismo político: Democracia ad intra y despotismo ad extra}

Las potencias metropolitanas, durante toda la Modernidad, y hasta el presente, ante el mundo postcolonial, han ejercido una "doble mo- 
ral". Hacia adentro (ad intra) han propuesto un "Principio democrático" como participación simétrica de los afectados en la creación de instituciones que organicen la procedimentalidad legítima, pero excluyendo de dicha participación a los esclavos, a los indios, a los pueblos coloniales durante la época colonialista, y muchos otros. Posteriormente, nunca los pueblos postcoloniales pudiron acceder a una soberanía popular real, sino que siguieron ejerciéndose sobre ellos presiones, opresiones, o exclusiones políticas, económicas, culturales, religiosas y militares.

Estados Unidos, bajo el gobierno de George W. Bush, es hoy la última expresión de ese "estado de guerra" permanente como horizonte argumentativo para negar a todos los demás pueblos o Estados un derecho de igualdad internacional. Este Estado hegemónico niega todo orden internacional supraestatal que pudiera limitar su hegemonía militar omnipresente (por sus naves que navegan en todos los océanos), omnipotente (por el poder destructor de su aviación) y omnisciente (por sus satélites espías y sus servicios de inteligencia).

Inesperadamente, mi argumentación filosófica ante la Ética del Discurso de hace algunos años, se torna más clara que nunca ${ }^{53}$. La "razón cínica", dije en otro trabajo, es la razón del que tiene el Poder y no está decidido a compartirlo. Por ello, no acepta argumentos, debates ni discusiones que puedan poner en cuestión su Poder. Por el contrario, para fundamentar su "aparente" pretensión democrática (ad intra), y ocultar su política despótica (ad extra), el argumento de John Locke enunciado más arriba permite adecuadamente aportar esa "apariencia" de fundamentación racional, no siendo sino una pseudo argumentación tautológica, que impide "entrar" en discusión racional alguna con otros Estados o pueblos. Cuando alguno de ellos opina lo contrario, el Estado hegemónico puede declararlo su enemigo, "terrorista", el que se ha puesto por propia culpa fuera de la ley y de las razones dadas por Dios (evidentemente, de las leyes y del Dios propios). Declarados a priori sin derechos humanos (como los prisioneros afganos en Guantánamo ${ }^{54}$ ), toda guerra contra ellos (sea la de Irak, Kosovo o Afganistán) es "guerra justa". El argumento es tautológico, y digo tautológico, porque el agente de la acción es el único juez que emite la razón que se propone para fundamentar su propia acción: el círculo se cierra en la pura identidad de la subjetividad autista, esquizoide, totalitaria. Estados Unidos define lo que es un terrorista, y declara 
hermenéuticamente a partir de su definición quiénes son terroristas (sin ningún juez humano, objetivo, exterior, internacional, que dé algún viso de justicia y equidad). Este juicio tautológico autoriza "legítimamente" (para el propio juez y el heroico ejecutor militar de la sentencia) la total destrucción del "terrorista". Se ha llegado a la total irracionalidad. La Totalidad totalizada emite un juicio desde su propio fundamento. El Otro ha sido aniquilado como Otro.

Por todo ello, podrá ahora comprobarse que se parte del supuesto sobre el que se ejerce la "razón cínica". La "razón cínica" usa siempre un pseudo argumento tautológico: es la razón que se da el Poder, y por la que no "entrará" jamás en una auténtica discusión (la de la "razón discursiva"), porque no está dispuesta, desde el punto de parti$\mathrm{da}$, a dejarse juzgar por ningún otro Poder. La decisión de no compartir el Poder, y de ejercerlo omnímoda y despóticamente sobre la humanidad, le impide "entrar" auténticamente en alguna discusión con "pretensión" de verdad. El Imperio no tiene "pretensión" de verdad, "tiene" la verdad, y sólo exige su aceptación —es el pseudo argumento que justifica la "guerra santa" ${ }^{5}$, otra denominación de la "guerra justa" de John Locke-. Un cierto "fundamentalismo de mercado" como expresaba George Soros- se encuentra detrás como actitud ética originaria.

Por ello, aunque se declara un Poder "democrático" con respecto a su propio pueblo (ad intra), sin embargo, su cinismo con respecto al Otro, a la Alteridad, al resto externo de la humanidad (ad extra), impide el ejercicio honesto y serio del Principio Democrático. ¿Cómo puede darse éticamente el reconocimiento de la igualdad humana a todos los miembros de la propia comunidad política, cuando se le atribuye a esa misma comunidad el derecho de declarar "inhumano" al resto de la humanidad? ¿Cómo puede un demócrata, que concibe la democracia, no meramente como un procedimiento político etnocéntrico, sino, al mismo tiempo, con exigencias normativas, ser despótico con los Otros, con los débiles, con los vencidos, con los postcoloniales...? El que mata a los otros insensiblemente, termina por suicidarse en el sinsentido moral.

La "doble moral" de las empresas transnacionales, que cumplen con las exigencias normativas ad intra, en el propio Estado metropolitano, y corrompen, simulan, roban, extraen ganancias excesivas ad ex- 
tra, terminan por corroer a toda la estructura normativa. La inmoralidad ad extra termina por imponerse ad intra. Es el caso de la transnacional Enron que, con su doble contabilidad y política financiera, engañó primero a los otros Estados y, al final, a los propios Estados Unidos (y se tiene sospecha que la costumbre se ha generalizado, dándose ya otros ejemplos dudosos, como en el caso de la IBM, la Coca Cola, el City Bank ya ligado al "blanqueo de dinero" de la droga, etc.).

\section{4. "Razón material" y "razón crítica": responsabilidad consensual de la comunidad de las víctimas}

Al "argumento de Locke", a la "razón cínica", debe oponérsele, (a) no sólo una argumentación material y crítica (que es necesaria, porque crea el consenso crítico de los oprimidos), que se enfrenta a la imposibilidad del Poder hegemónico de aceptar un argumento contrario (y que, por ello, no puede entrar a la discusión, porque simplemente tiene el Poder de evitar dicha discusión con los débiles), sino también (b) una organización politica del Poder material y crítico de los oprimidos, de los excluidos, de los que reciben en su corporalidad los efectos negativos de las decisiones tautológicas del "argumento de Locke". Tales Nuevos Movimientos Sociales se hicieron visibles en los grupos reunidos, entre otras manifestaciones recientes (como las de Seattle, Cancún, Génova, etc.), en el II Foro de Porto Alegre. En este último evento asistieron unas sesenta mil participantes, entre intelectuales orgánicos y militantes, que convivieron desde fines de febrero hasta comienzos de marzo de 2002. Se testimonió el hecho de que los "excluidos" constituyen entre sí "comunidades consensuales" descubriendo argumentos, comunicándose y viviendo experiencias que permitan ir rompiendo lentamente el Poder del Imperio y la pseudo argumentación lockeana. No es del dominador el tener el derecho de “juzgar" al Otro, su víctima. Es de la comunidad consensual y crítica, por ser y exponer las razones de las víctimas, el deber juzgar al Poder dominador despótico —usando la denominación lockeana-. Son los africanos esclavos, los indios conquistados, las comunidades coloniales y postcoloniales, los que deben mostrar que las pretendidas "guerras justas" fueron en realidad unas de las más injustas y perversas que puedan imaginarse en toda la historia mundial. Los trece millones de africanos esclavizados y los quince millones de indígenas muertos en 
el proceso de la conquista y la colonización muestran dos inmensos genocidios moderno-europeos que el "argumento de Locke" tornó visibles. Los esclavizados, conquistados y colonizados no eran humanos; eran bestias; hoy son los "terroristas" 56 . Para los imperios de turno no morían seres humanos; perecían "cosas" que habían sido destituidas de su humanidad previamente por el "argumento de Locke".

Llegamos así al problema filosófico de fondo ${ }^{57}$. A la razón estratégica del cínico, que se funda en el Poder para proferir un pseudo argumento tautológico (el "argumento de Locke"), no puede oponérsele una mera razón discursiva, porque el cínico no "entra" en dicha discusión. La filosofía de la liberación sabe, en cambio, enfrentar estratégica y teóricamente la situación, pero lo hace abriendo otros frentes.

En primer lugar, muestra la tautología del pretendido argumento autorreferente. En segundo lugar, enfrenta al Poder hegemónico desde el contrapoder antihegemónico de los Nuevos Movimientos Sociales (feminismo, antiracismo, afirmación de las culturas negadas por el colonialismo, liberación de las naciones periféricas postcoloniales, de las clases dominadas, de las etnias excluidas, de la tercera edad, de los niños, de las generaciones futuras a través del problema ecológico, etc., cuyas "redes" se fortalecieron mundialmente en el Foro de Porto Alegre). En tercer lugar, la fundamentación antiescéptica (del escepticismo de la razón hegemónica, subproducto cómplice de la dominación, como en el caso de un Richard Rorty, o del movimiento postmoderno) no se dirige a una mera afirmación de la razón en general, sino para dar argumentos racionales a las indicadas comunidades de liberación de los Nuevos Movimientos Sociales, a fin de legitimar a la "razón crítica": (a) tanto por sus contenidos (la razón práctico-material crítica, que justifica no sólo la producción y reproducción de la vida humana en comunidad con pretensión de universalidad, sino su desarrollo desde la afirmación de las víctimas ${ }^{58}$ ), (b) como por su validez (la razón discursiva crítica, desde el consenso de los excluidos contra el proceso hegemónico que profiere autorreferentemente el "argumento de Locke") ${ }^{59}$ y (c) por su factibilidad crítica (la praxis propia de la liberación, que supone la toma de conciencia y la organización de las víctimas "negadas" en su Alteridad por el Poder hegemónico) ${ }^{60}$.

Por ello, si es verdad que todo régimen democrático debe "poner límites"(1) y por ello hay inevitables exclusiones - los ciudadanos de otros Estados, aún reconocidos como tales-, lo que deseamos recal- 
car es que la filosofía política de Estados Unidos y Europa no vislumbra la diferencia ente (a) la situación de "estado de derecho" en el "centro" del sistema-mundo actual (el "Grupo de los Siete", siendo seis de ellos semiperiféricos de la superpotencia norteamericana) y (b) la situación política de los Estados postcoloniales periféricos (en el África, Asia y América Latina). Dicha diferencia es un efecto negativo de un "estado de guerra" permanente que se originó con la Modernidad, con la conquista de América en 1492 como sistema colonial, con el capitalismo como acumulación originaria de los metales preciosos americanos y con la trata de esclavos, acumulación acrecentada siglo por siglo y aumentada de manera nunca observada desde finales de la llamada Segunda Guerra Mundial (1945) y en especial desde 1989. Los Estados periféricos postcoloniales siguen sufriendo una imposibilidad estructural de alcanzar un grado de desarrollo y autonomía mínima, aceptable para poder establecer sistemas políticos democráticos -donde pudiera ejercerse la soberanía de los pueblos-. Hablar en estos Estados postcoloniales de un sistema democrático, supondría el dejar de sufrir el constante acoso de las potencias centrales, que agobian permanentemente sus explotadas economías en un grado tal, que los pueblos miserables terminan por expresar su desesperación, como aun las clases pequeño burguesas (no se diga las marginales) de Argentina en los recientes sucesos del 19 al 20 de diciembre de 2001. Este hecho manifiesta un "malestar" reciente entre los pueblos, que inicia que la democracia debe ser redefinida, para no inscribirse exclusivamente dentro de un procedentalismo que ya no se sostiene (siendo sólo el momento de pura legitimidad formal de la política) cuando la reproducción misma de la vida es puesta en cuestión (el movimiento políticoecológico-económico o material de la vida). Las masas hambrientas gritan: “iPan y trabajo!"62, como momento constitutivo de la política, y como condición del consenso que funda la legitimidad formal. No hay representación o consenso sin "ciudadanos vivos", y en el mundo periférico postcolonial esto no está garantizado de ninguna manera, dado el inmenso grado de transferencia de plusvalor que, procedente de los países explotados, sigue fluyendo hacia el "centro" - privilegio de los países centrales, no sólo Estados Unidos, sino también Europa, Japón y algunos otros-. Democracia y reproducción aceptable de la vida de los ciudadanos son dos aspectos del bien común; es la justa articulación del aspecto formal de legitimidad discursiva y el aspecto 
material de satisfacción reproductiva de la vida.

En último término, el "argumento de Locke" ocultaba que el Estado metropolitano (hoy, en último término, norteamericano) justificaba la negación de la vida del Otro, del esclavo, del indígena, del colono periférico, de todos los excluidos actuales del mercado. El cínico pretende justificar éticamente la negación de la vida del Otro; el escéptico pretende justificar moralmente la negación de la posibilidad de la utopia del poder vivir, del pretender tener un consenso crítico antihegemónico, del desear una "vida mejor" (no sólo una "vida buena"). Tres negaciones que hacen a la política una praxis antidemocrática, bajo la apariencia de cumplir ad intra con las exigencias liberales de la democracia.

Podríamos expresar, para concluir, que el proyecto utópico de Kant de una "Paz perpetua" ha dejado lugar en el presente y en el orden de la realidad geopolítica y militar a un proyecto de una "Guerra perpetua". No es ya que "la guerra es el origen de todo", como para Heráclito de Éfeso, sino que "el estado de guerra es el ser mismo permanente de todo". iUna ontología de la muerte!

\section{NOTAS}

1. Simon \& Shuster, Nueva York, 1996. Digo militar, porque una de las conclusiones finales del autor es la de "mantener la superioridad tecnológica y militar de Occidente sobre otras civilizaciones" (Trad. castellana: Paidós, México, 2001, p. 374.). Cuando escribe "Occidente", debe leerse "Estados Unidos".

2. "The New Sovereignists. American Exceptionalism and its False Prophets", en Foreign Affuirs, vol. 79, 6, Nov.-Dec. 2000, pp. 9-15. Bradley y Goldsmith escriben en Harvard Law Review (1977) que "not only does the Unites States have the power to reject international regimes, but in many instances the federal government has a constitutional duty to reject them" (Spiro, p. 113).

3. Open Society. Reforming Global Capitalism, Public Affairs, New York, 2000, pp. 330 ss.

4. "It may be a shocking thing to say, but the United States has become the greatest obstacle to establishing the rule of law in international affairs" (Op. cit., p. 333).

5. Michael Hardt-Antonio Negri, Empire, Harvard University Press, Cambridge (Mass.), 2000, donde el "Imperio" se volatiliza, el Estado se anarquiza y el "ciudadano global" queda sin mediaciones políticas estratégicas.

6. Véase Robin Blackburn, The Making of New World Slavery. From the Baroque to the Modern. 1492-1800. Verso, London, 1999, pp. 235ss.

7. Op. cit., p. 249

8. Hegel, por ejemplo, repite la argumentación lockeana, ya que la relación externa entre los Estados (contra la opinión de Kant) vuelve al "estado de naturaleza", 
siendo la única relación posible: “La guerra tiene una significación superior [...] Los pueblos que no quieren soportar, o que tiemblan ante la soberanía interior son conquistados por otros" (Rechtsphilosophie, \$324; Hegel, Werke, Suhrkamp, Frankfurt, 1971, vol. 7, pp. 492-493).

9. Véase el reciente trabajo de Franz Hinkelammert, "La inversión de los derechos humanos: el caso de John Locke", en Herrera Flores (Ed.), El vuelo del Anteo. Derechos humanos y crítica de la razón liberal, Desclée de Brouwer, Bilbao, 2000, pp. 79-113,

10. En el Encuentro de las Naciones Unidas sobre el racismo, celebrado el 7 de septiembre de 2001, en Sudáfrica, la Unión Europea no aceptó fácilmente reconocer a la esclavitud como un crimen contra la humanidad. Estados Unidos e Israel se retiraron del Encuentro bajo protesta.

11. Tema central de mi obra, Hacia una ética de la liberación latinoamericana, Siglo XxI, Buenos Aires, 1973, vols. 1-2.

12. Two Treatises on Civil Government, $\$ 4$; John Locke, Ensayo sobre el Gobierno civil, Aguilar, Madrid, 1976, p. 5.

13. Ibid., $\$ 6$, p. 6 .

14. Ibid, $\$ 7$, p. 7.

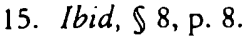

16. Ibid.

17. Ibid.

18. De nuevo: ¿quién juzga que alguien se ha opuesto a la ley natural? Locke respondería: "Cualquiera".

19. No hay que olvidar que esos pronombres, "nosotros" y "yo", que se usan en el texto, son el sujeto que juzga sobre el culpable, que se arroga la defensa del género humano, pero que, históricamente y de hecho, es la burguesía liberal triunfante en Inglaterra.

20. Ibid., $\$ 16$, p. 14 .

21. Ibid., $\$ 17$, p. 15.

22. Ibid., $\$ 19$, p. 16.

23. Ibid., $\$ 20$, p. 18.

24. Estados Unidos, en su política externa, muestra una doctrina hermenéutica en la que los Derechos Humanos tienen en su definición a ese país como "juez", última instancia, que declara lo que es o no es, en este caso, defensa o ataque de un Derecho Humano. Ningún tribunal fuera del propio Estado es aceptado como referencia. Se sobreentiende que en la relación entre los Estados nos encontramos, entonces, en el mejor de los caos, en el "estado de naturaleza" (Véase John Rawls, The Law of peoples, Harvard University Press, Cambridge, Mass., 1999). Rawls se cuida muy bien de distinguir entre la "law of People" y la "law of State". Los "States" exigirían un derecho internacional y el comenzar a promulgar un "International State", al menos, leyes e instituciones internacionales, que permitieran salir del "estado de naturaleza" a las relaciones entre los Estados. Rawls encuentra muy cómodo el estado razonable (de guerra) en el que su propio país (Estados Unidos) siga siendo el sujeto del juicio, el juez, de quien sea o no un "decent people" (p. 63). Es una obra completamente tautológica: la comunidad de liberales norteamericanos es la "última instancia" de todos los juicios políticos, 
incluyendo el saber cuándo se dan las condiciones de la "guerra justa" (pp. 89ss). Continúa paso a paso la argumentación de Locke.

25. Debe indicarse que Lévinas no habla de la "guerra", sino estrictamente del "estado de guerra", que, como veremos, es el "estado permanente" ad extra de los Estados Unidos desde su emancipación. La conquista del Far West, de México, del Pacífico y del Caribe, hasta su hegemonía mundial actual, ha sido un permanente, nunca interrumpido, "estado de guerra" ad extra - mientras que ad intra se pretende ser el líder del "estado civil" democrático. Veremos que esta contradicción es, in the long run, insostenible.

26. Totalité et Infinit. Essai sur l'Extériorité, Nijhoff, La Haye, 1968, Préface, p. IX.

27. Ibid., $\$ 176$; pp. 134-135.

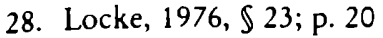

29. Es interesante que, para Ginés de Sepúlveda, el indigena que lucha contra el conquistador español (en propia defensa, para Bartolomé de las Casas) tiene la "culpa" de rechazar el ser civilizado. El mismo Kant en la definición de Aufklärung incluye esta "inmadurez culpable" (verschuldeten Unmundigkeit) (véase E. Dussel, The Invention of the Americas. The Eclipse of "the Other" and the Myth of Modernity, Continuum, New York, 1995, cap. 1). A la victima se la transforma primero en culpable, de manera que el criminal se juzga (invirtiendo la cuestión) asesinado por su víctima. El victimario reclama a su víctima el haberlo victimado. De otra manera, Locke, el esclavizador inglés, acusa al esclavo africano por haberle exigido cumplir la tarea de esclavizarlo, y por ello demandará aún reparaciones de los gastos a los que su víctima le ha obligado a efectuar.

30. Locke debería probar que los pobres campesinos bantúes inocentes, atrapados como animales y vendidos como "mercancías" merecieron dicha pena. Bartolomé de las Casas vio estas cuestiones con mayor claridad racional y lógica.

31. Por la propia argumentación de Locke nadie puede "perder el derecho a su vida", porque nadie "tiene" tal derecho: ¿Cómo podría tenerse "derecho a la vida", si la vida es el presupuesto y el fundamento de todos los derechos? Para tener "derecho a la vida", habría que ser un sujeto de derecho anterior a la propia vida, lo cual es absurdo. Si no se tiene "derecho" ni "poder" sobre su propia vida, menos se puede perder lo que nunca se tuvo. La inteligencia de Locke en este punto, pareciera que ha quedado oscurecida por la pasión inmoderada de querer justificar su business y el de su patria: la trata de esclavos.

32. Esto supone una teoría de la "guerra justa" y del "estado de guerra", en la que el vencedor tuviera ahora "derecho a la vida del otro". Pero, nuevamente, si ni siquiera el sujeto humano viviente tiene derecho a su propia vida, menos aún de la de un tercero. Nadie puede tener "derecho sobre la vida ajena", o habría que probarlo. Locke, nuevamente, afirma un absurdo por mera tradición tautológica, totalitaria, contraria al dogma liberal: "la libertad es la base de todo" (Ibid., $\$ 17 ;$ p. 15).

33. Aquí Locke cae ya en un cinismo que supera al de Ginés de Sepúlveda. En primer lugar, al expresarse sobre una persona humana como lo que se "tiene en poder suyo" - cosificación de la Alteridad, que muestra la bajeza ética del filósofo inglés-, y en segundo lugar, por la manera que expresa en este texto (y en otros que citaré) lo que puede hacerse con esa "cosa" que se "tiene" (no sólo usarlo en el trabajo o como objeto de sexo sino torturarlo y hasta matarlo por puro capricho). ¿De dónde ha sacado nuestro autor esa destitución ética absoluta del Otro? 
34. Locke alcanza aquí un sadismo increíble, consolando al esclavo misericordiosamente con el suicidio. Ante un juicio tan brutal, bestial, el lector queda enmudecido, absorto, silencioso...

35. Ibid.

36. Ibid., $\ 23$; p. 20.

37. Ibid., $\$ 33$; p. 27. Aún dirá mas extensamente: “Los gobiernos no pueden originarse primitivamente [...], y las sociedades políticas no pueden fundamentarse en nada que no sea el consentimiento del pueblo" (Ibid., $\$ 175 ;$ p. 134).

38. Ibid., $\$ 45 ;$ p. 36 .

39. Como si todos los pueblos fueran agricultores.

40. Ibid., $\$ 184 ;$ p. 143.

41. Ibid., p. 136.

42. Escribe más adelante: "El vencedor, si ha hecho la guerra por una causa justa, posee un derecho despótico sobre las personas [...] que han tomado parte en la misma, y lo posee también a indemnizarse de los perjuicios recibidos y del costo de la guerra..."

43. Ibid., \178; p. 137.

44. Ibid., $\ 182 ;$ p. 140.

45. Pol., 1, 2, 1255b 16-17. Locke debió leer pocas líneas después de la definición del "esclavo por naturaleza" esta distinción: "El señorío político se ejerce sobre hombres libres por naturaleza; el despótico, sobre los esclavos por naturaleza" (Ibid., 1255b 17-18).

46. Está de más decir que el tal "poder despótico" es injustificable, menos aún en un estado de naturaleza (ni siquiera un animal puede cumplir tal definición, o la tal especie se habría extinguido prontamente), desde cualquier punto de vista ético, etnográfico o histórico, y describe simplemente una voluntad tiránica, irracional y totalitaria, autodestructiva.

47. Uno se pregunta qué agrega el poner aquí a "Dios" en esta expresión de cinismo. Pareciera ampararse en la divinidad para expresar un pseudo argumento totalitario.

48. Como no ha cumplido el "enemigo" con la ley establecida, queda "fuera de la ley", y como no aceptó los "recursos pacíficos", se le aplican los recursos más violentos. Aunque el pobre campesino africano hubiera estado fuera de la ley y no hubiera sido pacífico (lo cual es falso, porque nunca estuvo fuera de "sus costumbres" y nunca atacó a ningún europeo), no perdería por ello sus derechos que tiene como persona humana, y no podría tratárselo como una "fiera" a la que se la puede matar porque "le agrade" (al sádico).

49. Ibid., \$172; p. 132.

50. Ibid., $\$ 180 ;$ p. 138. Locke justifica por ello mismo la conquista de América, porque "el poder que un conquistador adquiere sobre aquellos a quienes vence en una guerra justa es totalmente despótico" (Ibid., $\$ 179$; p. 138). Puede concluirse que el esclavo africano, el indio americano y el mundo colonial son negados e ignorados en su derecho en la filosofía política del fundador del pensamiento liberal.

51. Antes fueron las "potencias del Eje" (desde la crisis de los años treinta), después los "comunistas" (en tiempos de la "Guerra Fría"), pero últimamente estaba fal- 
tando un "enemigo" creíble, consistente, suficiente. Los antiguos "subversivos comunistas" han dejado lugar ahora a los "terroristas".

52. Claro que "Dios" hará conocer su juicio en el "Juicio Final", y para los geopolíticos del Pentágono, dicho juicio deja suficiente tiempo como para ganar las guerras empíricas de la historia - que son las que le interesan-. C. Schmitt, por otra parte, tampoco tiene otro criterio para determinar a su enemigo. Es tan tautológico como Locke.

53. Véase mi ponencia "Del escéptico al cínico", en E. Dussel, Apel, Ricoeur, Rorty y la Filosofia de la Liberación, Universidad de Guadalajara, Guadalajara (México), 1993; en inglés, en E. Dussel, The Underside of Modernity, Humanities Press, New Jersey, 1996, pp. 64-72.

54. Si se los aceptara como "prisioneros de guerra" habría que aplicárseles las Convenciones internacionales, como la de Ginebra. Pero, para negarles que sean prisioneros "de guerra", debería fundamentarse que no ha habido guerra en Afganistán, porque no se había declarado tal guerra a los talibanes, meros "terroristas" y, por tanto, "sin derechos", a los que puede matárselos como lobos o leones peligrosos. Pero en ese caso, la agresión a Afganistán sería un acto "terrorista", porque se atacó a otro Estado sin cumplir las condiciones para un ataque semejante dentro de un criterio ético internacional. Lo que acontece es que Estados Unidos, en permanente estado de guerra, no logra entender que está usando el "argumento de Locke", pero ese argumento, por tautológico es irracional, inmoral, y no puede proferirse "en público", sino sólo entre los "amigos" de la misma "mafia" o de una "banda de ladrones"; en un "nosotros" entre los que los argumentos tautológicos son aceptados como verdaderos sin mayores exigencias lógicas.

55. Leemos an el diario que John Ashcroft, nombrado Procurador General por George W. Bush "pidió esta semana lanzar una guerra santa en defensa de la civilización y contra el terrorismo" (La Jornada, México, 24 de febrero de 2002, p. 31). Bush, que había hablado de "cruzada" (cristiana contra los musulmanes), al inicio de la guerra contra Afganistán, nuevamente se refirió a una "cruzada" en su viaje a Japón (en el mes de febrero), hecho criticado por Zogby (Ibid.).

56. Es evidente que siempre ha habido terroristas. Lo criticable del hecho es que no se acepten tribunales internacionales, como el Consejo de Seguridad de Naciones Unidas, que pudiera intervenir en una definición de su concepto. En realidad, las resoluciones de dicho Consejo nunca son aceptadas por Estados Unidos o por Israel. Vemos, entonces, que las "mil reuniones, discusiones, acuerdos" de poco valen cuando se oponen a la "Voluntad de Poder" del Imperio.

57. Véase E. Dussel, "From the Skeptic to the Cynic", en The Underside of Modernity, Humanities Press, New Jersey, 1996, pp. 64ss.

58. Véase E. Dussel, Ética de la liberación en la edad de la globalización y la exclusión, Trotta, Madrid, 3" edición, 2000, caps. 1 (pp. 15ss) y 4 (pp. 85ss). Lo que no había enunciado claramente en dicha ponencia eran dos cuestiones. La primera, que el cínico no "entra" en una discusión honesta, no sólo porque tiene el Poder, sino porque tiene un argumento, el "argumento de Locke" (pseudo argumento autoreferente que se hace evidente para el dominador y sus "amigos"). La segunda, que la fundamentación que hay que efectuar, no se dirige tanto a una justificación en general de la razón ambigua de los grupos dominantes (como en 
el caso de K.-O. Appel), sino como justificación de una razón consensual y material critica de las comunidades excluidas, dominadas, negadas. El filósofo crítico (filosofía de liberación)) argumenta a favor de grupos empíricos que necesitan dicha fundamentación para su acción estratégica liberadora, innovadora, creadora.

59. Ibid., caps. 2 y 5 .

60. Ibid., caps. 3 y 6 .

61. Véase, por ejemplo, Iris Marion Young, Inclusion and Democracy, Oxford University Press, Oxford, 2000; Chantal Mouffe, The Democratic Paradox, Verso, Londres, 2000.

62. En tiempos de las dictaduras peritericas, instaladas desde el Pentágono, como en el caso de la dictadura de Augusto Pinochet contra el gobierno democrático de Salvador Allende en 1973, golpe de estado decidido y promovido por Henty Kissinger desde el Departamento de Estado norteamericano (como en este febrero de 2002 se está promoviendo de la misma manera el golpe de estado contra Hugo Chávez en Venezuela, por pretender tener una política propia en la optr, y con respecto al petróleo), en tiempo de las dictaduras - repito- se gritaba "iPan, paz y trabajo!". Ahora no se grita "iPaz!", porque la "Guerra Sucia" de los militares ya no es necesaria para el Imperio. Pero la vida del pueblo oprimido y excluido sigue gritando el aspecto material de la política: comida y empleo (porque el capitalismo ha destruido toda otra manera de reproducir la vida). En el II Foro de Porto Alegre (2002), sin embargo, pudo observarse el nacimiento de una "economía solidaria", que cuenta solamente en Argentina dos millones de miembros. El movimiento se expresó ya hace años con la obra de Luis Razeto Migliaro, publicada en 1982, Empresas de trabajadores y economia de mercado, Programa de Economía de Trabajo, Santiago de Chile, seguido de Economía de Solidaridad y mercado democrático, PE.l, Santiago, 1985, vol. 2 y 1988, vol. 3. Se trata de la mera subsistencia de una población de excluidos, marginales, que antes de morir de hambre reinventan un sistema de "trueque" con moneda propia, por la organización de la producción y el consumo dentro de una comunidad barrial o local cerrada. iEl mundo de los excluidos sobrevive! 